\title{
Direct Transformation of Esters into Arenes with 1,5-Bifunctional Organomagnesium Reagents
}

\author{
Achim Link, Christian Fischer, and Christof Sparr* \\ Dedicated to Professor Steven V. Ley on the occasion of his 70th birthday
}

Abstract: A direct transformation of carboxylic acid esters into arenes with 1,5-bifunctional organomagnesium reagents is described. This efficient and practical method enables the onestep defunctionalization of various carboxylic acid esters to prepare benzene, anthracene, tetracene, and pentacene derivatives. A double nucleophilic addition of the 1,5-organodimagnesium reagent to the ester is followed by an immediate 1,4-elimination reaction that leads to the direct [5+4] formation of a new aromatic ring.

rganomagnesium reagents have an ideal reactivity for carbon-carbon bond forming reactions, as is evident from the enduring relevance of Grignard chemistry. ${ }^{[1]}$ In recent years, we have experienced a dramatic improvement in the acces-sibility of organomagnesium compounds by the emergence of mild halogen-metal exchange methods. Seminal studies by Knochel and co-workers have shown that Grignard reagents bearing various reactive functional groups can be readily prepared and utilized. $^{[2]}$ Compared to the insertion of elemental magnesium into the $C \mathcal{C}$ X bond, these exchange reactions are characterized by an exceptional range of applications. For instance, Oshima et al. and researchers at Banyu Pharmaceuticals have reported on the highly efficient conversion of (Z)-alkenyliodides without chelating groups to form the corresponding alkenylmagnesium compounds by using lithium trialkylmagnesates $\left(\mathrm{R}_{3} \mathrm{MgLi}\right) .^{[3]}$ These magnesiations proceed with complete retention of double-bond configuration and without undesired elimination reactions.

Considering this remarkable advancement, we anticipated the development of new synthetic methods based on bifunctional organomagnesium compounds resulting from a double halogen-metal exchange. ${ }^{[4]}$ A stereospecific double halogenmetal exchange of $(\mathbf{1 Z , 4 Z ) - 1 , 5 - d i h a l o p e n t a - 1 , 4 - d i e n e ~} 1$ with an exchange reagent 2 would lead to a 1,5-bifunctional organomagnesium reagent 3 (Scheme 1 a). A subsequent double nucleophilic addition of reagent $\mathbf{3}$ to carboxylic acid ester 4 generates cyclohexa-2,5-dienolate $\mathbf{5}$, which is directly transformed into an arene by means of a 1,4-elimination reaction (Scheme $\mathbf{1}$ b).

[*] A. Link, C. Fischer, Dr. C. Sparr

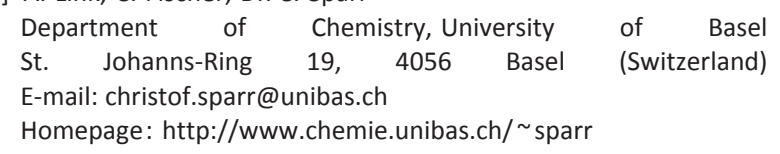

a) Double Halogen-Metal Exchange

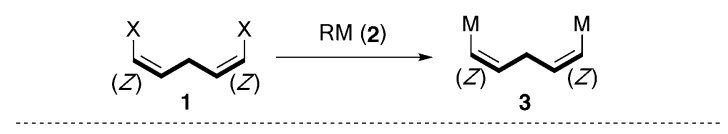

b) Direct Ester to Arene Transformation

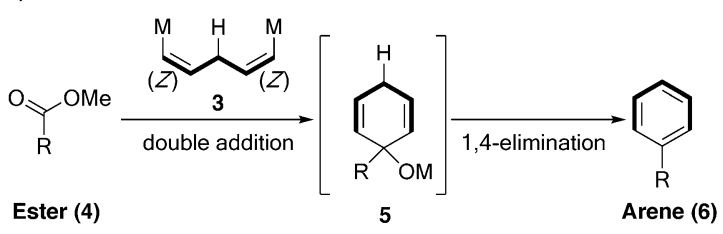

Scheme 1. a) Double halogen-metal exchange to form (1Z,4Z)-1,5dimetalla-1,4-pentadiene 3. b) Direct transformation of carboxylic acid ester 4 into arene 6 through the double addition of $(1 Z, 4 Z)-1,5-$ dimetalla-1,4-pentadiene 3 followed by a 1,4-elimination.

An analogous [5 14$]$-formation of an aromatic ring with known methods would require several stages and harsh reaction conditions. ${ }^{[5]}$ Given the high availability of carboxylic acid esters, a mild one-step process would give expedient access to compounds typically prepared by transition-metal-catalyzed cross-coupling reactions from complementary sub-strates. ${ }^{[6]}$ Intrigued by this prospect, we evaluated the feasibility of a direct conversion of esters into arenes with 1,5-bifunctional organomagnesium compounds.

We started our investigations with the development of a concise synthesis of (1Z,4Z)-1,5-diiodopenta-1,4-diene (1 a) from readily available starting materials (Scheme 2). ${ }^{[7]}$ Two equivalents of ethynylmagnesium bromide (7) were added to ethyl formate (8), followed by diiodination with $\mathrm{N}$-iodosuccinimide. The subsequent (Z)-selective double alkyne reduction with diimide and a trifluoroacetic acid mediated dehydroxylation with triethylsilane provided (1Z,4Z)-1,5diiodopenta-1,4-diene (1a) in $41 \%$ yield over four steps. ${ }^{[8]}$

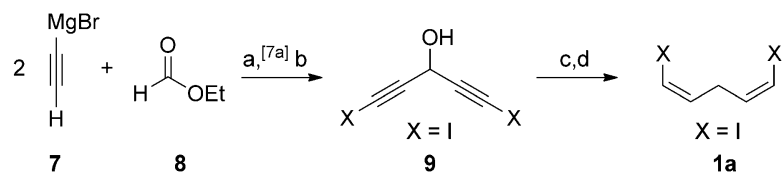

Scheme 2. Synthesis of (1Z,4Z)-1,5-diiodopenta-1,4-diene 1 a. a) THF, $\mathrm{RT}$; b) N-lodosuccinimide, $\mathrm{AgNO}_{3}$, acetone, $\mathrm{RT}$; c) $\mathrm{KO}_{2} \mathrm{CN}=\mathrm{NCO}_{2} \mathrm{~K}$, pyridine, $\mathrm{AcOH}, \mathrm{MeOH}, \mathrm{RT}$, then aqueous $\mathrm{HCl}$; d) $\mathrm{Et}_{3} \mathrm{SiH}, \mathrm{CF}_{3} \mathrm{CO}_{2} \mathrm{H}$, $\mathrm{CH}_{2} \mathrm{Cl}_{2}, 08 \mathrm{C} ; 41 \%$ over four steps. 
Table 1: In situ generation of reagent $3^{[a]}$ and optimization of the reaction parameters for the direct ester to arene transformation. ${ }^{[b]}$
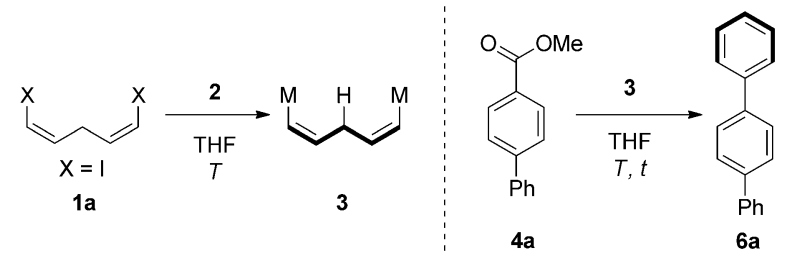

\begin{tabular}{|c|c|c|c|c|}
\hline Entry & X-M Exchange Reagent (2) & $T\left[{ }^{\circ} \mathrm{C}\right]$ & $t$ & Yield $[\%]^{[c}$ \\
\hline 1 & $n B u L i i^{[d]}$ & -40 & $2 \mathrm{~h}$ & 46 \\
\hline 2 & $i \operatorname{PrnBu}{ }_{2} \mathrm{MgLi}^{[\mathrm{e}]}$ & 0 & $30 \mathrm{~min}$ & 70 \\
\hline 3 & $i \operatorname{PrnBu} \mathrm{u}_{2} \mathrm{MgLi}$ & 0 & $30 \mathrm{~min}$ & 70 \\
\hline 4 & $n \mathrm{Bu}_{3} \mathrm{MgLi}$ & 0 & $30 \mathrm{~min}$ & 64 \\
\hline 5 & sBunBu ${ }_{2} \mathrm{MgLi}$ & 0 & $30 \mathrm{~min}$ & 56 \\
\hline 6 & $i \operatorname{PrnBu}{ }_{2} \mathrm{MgLi}$ & -20 & $30 \mathrm{~min}$ & 69 \\
\hline 7 & $i \operatorname{PrnBu}_{2} \mathrm{MgLi}$ & -20 & $2 \mathrm{~h}$ & 82 \\
\hline 8 & iPrnBu ${ }_{2} \mathrm{MgLi}$ & -40 & $2 \mathrm{~h}$ & 61 \\
\hline 9 & $i \operatorname{PrnBu}{ }_{2} \mathrm{MgLi}^{[f]}$ & -20 & $2 \mathrm{~h}$ & 70 \\
\hline 10 & $i^{P r n B u}{ }_{2} \mathrm{MgLi}^{[g]}$ & -20 & $2 \mathrm{~h}$ & 73 \\
\hline
\end{tabular}

[a] Reactions performed with $200 \mu \mathrm{mol} 1 \mathrm{a}$ and $200 \mu \mathrm{mol} 2$ for $5 \mathrm{~min}$ at $T$. [b] $100 \mu \mathrm{mol} 4 \mathrm{a}$ and in situ generated 3 for $t$ at $T$ followed by aqueous work-up $\left(\mathrm{HCl} 1.0 \mathrm{~mol} \mathrm{~L}^{-1}\right)$. [c] Yield of isolated product 6a. [d] Reaction was performed in $\mathrm{Et}_{2} \mathrm{O}$. [e] Purchased from Sigma-Aldrich, No. 683418. [f] Reagent $3 \mathrm{a}$ was kept $2 \mathrm{~h}$ at $-20^{\circ} \mathrm{C}$ prior the reaction with $4 \mathrm{a}$. [g] $160 \mu \mathrm{mol} 1 \mathrm{a}$ and $160 \mu \mathrm{mol} 2$.

We next explored different methods for the double metalation to form 1,5-organodimetallic reagents 3 (Table $1, \mathrm{M}=\mathrm{Li}$ or $\mathrm{Mg}$ ). The two-fold iodine-lithium exchange at $\$ 408 \mathrm{C}$ described by Jutzi led to a highly reactive dilithium species $^{[9]}$ capable of converting methyl 4-phenylbenzoate (4a) into p-terphenyl (6a) in a promising yield of $46 \%$ (Table 1 , entry 1 ). Since no product formation was observed after a transmetalation reaction with $\mathrm{MgX}_{2}$ and since the direct reaction of 1 a with elemental magnesium was ineffective to give the corresponding organomagnesium compound, we focused on (Z)-alkenyliodidemagnesium exchange reactions. ${ }^{[10]}$ However, even after prolonged reaction times, the reaction of $1 \mathrm{a}$ with $\mathrm{iPrMgCl} \cdot \mathrm{LiCl}$ resulted mainly in monometala-tion. In contrast, $\mathrm{sBu}_{2} \mathrm{Mg} \cdot \mathrm{LiCl}$ enabled complete halogenmetal exchange at both the 1- and 5-position. Nevertheless, the resulting reagent was unproductive in the conversion of $4 a$ to the desired $p$ terphenyl (6a). ${ }^{[11]}$ Given the extraordinary modu-lation 2 aptitude of magnesate reagents, we treated $1 \mathrm{a}$ with equimolar amounts of commercially available heteroleptic iPrnBu${ }_{2} \mathrm{MgLi}^{[12]}$ Even at $08 \mathrm{C},(\mathrm{Z}, \mathrm{Z})-1,4-$ pentadiene-1,5-diyl $3 \mathrm{a}^{[13]}$ was efficiently formed within 5 min and a significant increase in yield for the direct carboxylic acid ester to phenyl conversion was achieved 3 (Table 1, entry 2, $70 \%$ ). Alternatively, iPrnBu $\mathrm{MgLi}^{2}$ can effortlessly be prepared from iPrMgCl and two equivalents of nBuLi (Table 1, entry 3). We further examined $\mathrm{nBu}_{3} \mathrm{MgLi}$ and $\mathrm{sBu}-\mathrm{nBu} \mathrm{u}_{2} \mathrm{MgLi}$ to identify iPrnBu${ }_{2} \mathrm{MgLi}$ as the ideal halogen-metal exchange reagent (Table 1 , entries 4 and 5 versus entry 3). A marked improvement in yield was obtained after optimizing the reaction time and temperature, and subsequent reactions were carried out for $2 \mathrm{~h}$ at $\$ 208 \mathrm{C}$. The best results were obtained by the immediate use of the in situ prepared reagent $3 \mathrm{a}$ and a compensation of decomposition pathways with an excess of the reagent (Table 1, entries 9 and 10 versus entry 7).

With the optimized reaction conditions in hand, we explored the substrate scope of the direct transformation of carboxylic acid esters into benzenes (Table 2). A comparable outcome was obtained with substrates bearing electronwithdrawing groups, whereas the lower reactivity of ester substrates with electron-donating groups was evident from a lower yield (Table 2, entry 1 versus entries 2-4). Nonetheless, phenyl-substituted heterocyclic compounds could be prepared in synthetically meaningful yields (Table 2, entries 5 and 6). Even alkyl and alkenyl esters were amenable to form the corresponding benzene derivatives $6 \mathrm{~g}$ and $6 \mathrm{~h}$, thus highlighting the broad applicability of the method (Table 2, entries 7 and 8). Furthermore, when using an additional equivalent of reagent 3 a, even a protic substrate was tolerated and efficiently converted into the corresponding benzene derivative 6 i (Table 2 , entry $9,80 \%$ ).

Having developed a method for the direct conversion of carboxylic acid esters into benzene derivatives, we turned our attention to 1,5-bifunctional diarylmagnesium reagents $3 b-3 d$ for the transformation of esters into anthracene, tetracene, and pentacene derivatives. The direct addition of metallic

Table 2: Scope of the direct ester to benzene transformation using 1,5-bifunctional organomagnesium reagent $3 \mathrm{a}^{\left[{ }^{[a]}\right.}$

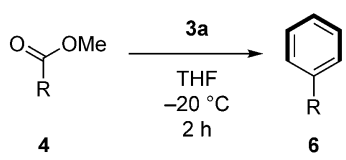

Entry Product ${ }^{[\mathrm{b}]}$ Entry Product ${ }^{[\mathrm{b}]}$

$6 a, 82 \%$

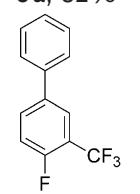

$6 \mathrm{~b}, 80 \%$

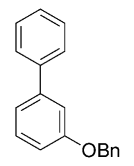

$6 c, 59 \%$
$6 d, 57 \%\left[{ }^{[c]}\right.$<smiles>c1ccc(-c2cccnc2)cc1</smiles>

6 e, $72 \%$

6<smiles>c1ccc(-c2ccnc3ccccc23)cc1</smiles>

$6 f, 68 \%$
8

$6 \mathrm{~g}, 68 \%$

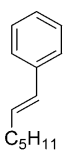

9

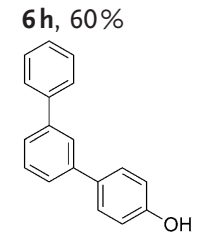

$6 i, 80 \%[c]$ [a] Reactions performed with $100 \mu \mathrm{mol} 4$ and in situ generated 3 a (from $200 \mu \mathrm{mol}$ $1 \mathrm{a}$ and $200 \mu \mathrm{mol} 2)$ for $2 \mathrm{~h}$ at $-20^{\circ} \mathrm{C}$ followed by aqueous work-up $(\mathrm{HCl}$ $1.0 \mathrm{~mol} \mathrm{~L}^{-1}$ ). [b] Yield of isolated product. [c] From $300 \mu \mathrm{mol} 1 \mathrm{a}$ and $300 \mu \mathrm{mol} 2$. 
Table 3: Scope of the direct transformation of esters into anthracenes, tetracenes, and pentacenes using 1,5-bifunctional organomagnesium reagents $3 \mathrm{~b}-3 \mathrm{~d}$. ${ }^{\text {[a] }}$

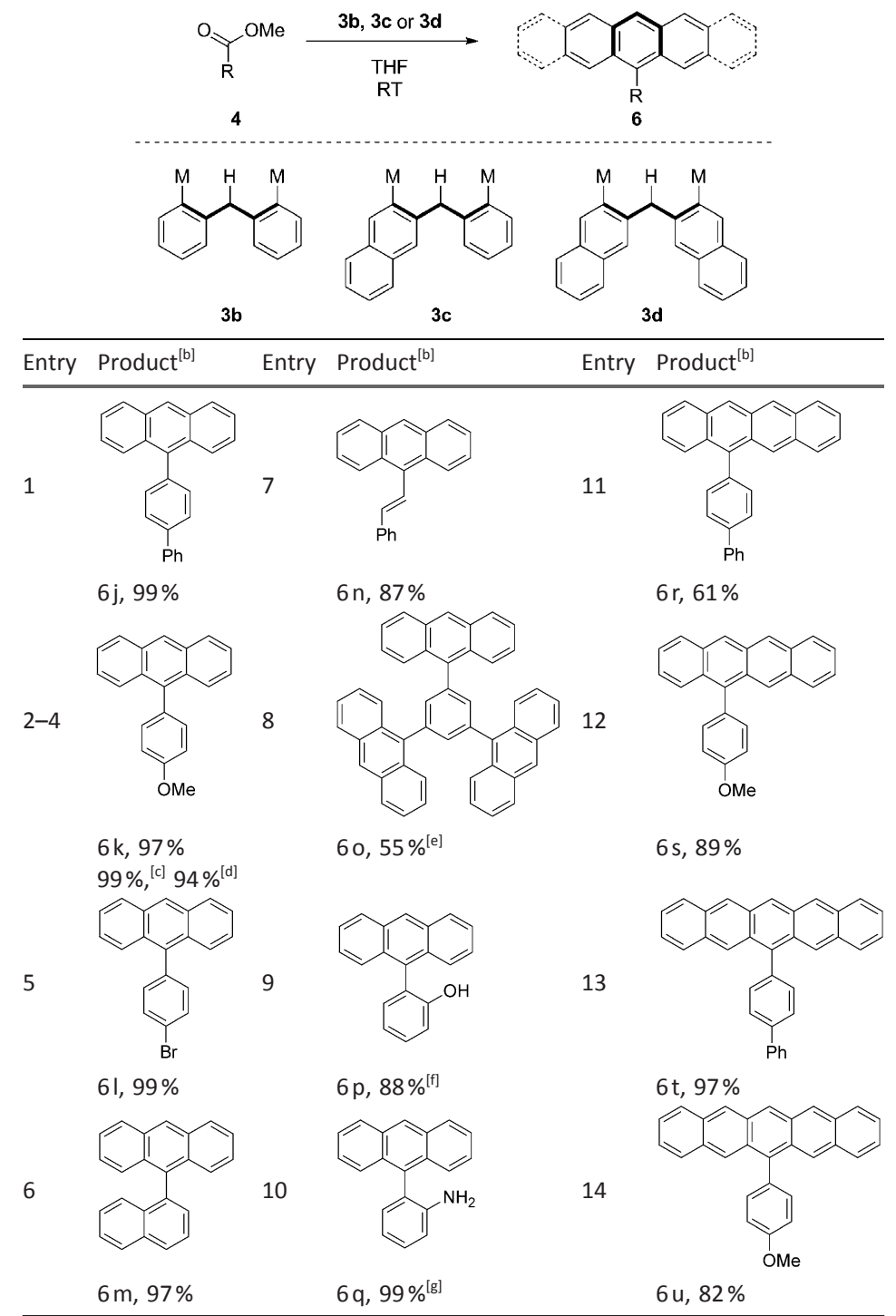

[a] Reactions performed with $100 \mathrm{mmol} 4$ in $1.0 \mathrm{mLTHF}$ and $140 \mathrm{mmol} 3$ for $4 \mathrm{~h}$ at RT followed by aqueous workup $\left(\mathrm{HCl} 1.0 \mathrm{~mol} \mathrm{~L}^{\mathrm{c1}}\right)$. [b] Yield of isolated product.

[c] $1.00 \mathrm{mmol}$ scale. [d] $10.0 \mathrm{mmol}$ scale. [e] Threefold ester to anthracene transformation with $420 \mathrm{mmol} 3 \mathrm{~b}$; the third aromatization was induced in a separate step through treatment with conc. $\mathrm{HCl}$ [f] $200 \mathrm{mmol} \mathrm{3b.} \mathrm{[g]} 240 \mathrm{mmol} 3 \mathrm{~b}$.

magnesium to o,o'-dibromodiarylmethanes led to the notably more stable reagents $3 b-3 d .^{[14]}$ To our delight, the union of $3 b$ and ester $4 \mathrm{a}$ resulted in the formation of anthracene derivative $6 \mathrm{j}$ with extraordinary efficiency (Table 3, entry 1, 99 $\%)$. A more electron-rich aryl ester could also be converted into the biaryl product in excellent yield (Table 3, entry 2). The scalability of the reaction was verified by increasing the reaction scale (Table 3, entries 3 and 4, $1.00 \mathrm{mmol}$ and $10.0 \mathrm{mmol})$. Moreover, the phenylanthracene with a bromo substituent and the naphthyl derivative with increased steric demand could also be obtained in remarkable yields (Table 3, entries 5 and 6, 99\% and $97 \%$ ). The reaction of an alkenylester underlines the wide substrate scope (Table 3, entry $7,87 \%$ ) and a triple carboxylic acid ester to arene transformation highlights the robustness of the reaction
(Table 3, entry 8, 55\% for three anthracene formations). With an excess of reagent $3 \mathrm{~b}$, esters with protic functional groups could also be efficiently converted (Table 3, entries 9 and 10). Particularly gratifying was that tetracene derivatives substituted at the 5-position were also obtained in high yields (Table 3, entries 11 and 12). We furthermore found that by working in the dark with degassed THF, even monosubstituted pentacene derivatives were accessible after isolation by crystallization (Table 3, entries 13 and 14). These synthetically challenging monosubstituted pentacenes emphasize the advantages of the direct ester to arene transformation. The mild reaction conditions of the method also allow the preparation of sensitive compounds in high yields.

In summary, we have developed a method for the direct transformation of carboxylic acid esters into the corresponding benzene and acene derivatives by the use of 1,5-bifunctional organomagnesium reagents. An in situ iodine-magnesium exchange with lithium trialkylmagnesates enabled the generation of dialkenyldimagnesium reagents for the formation phenyl derivatives. In contrast, the diaryldimagnesium reagents were accessible when using metallic magnesium from o,o'-dibromodiarylmethane precursors, which allowed the efficient synthesis of anthracenes, tetracenes, and pentacenes. Treatment of carboxylic acid esters with the 1,5bifunctional organomagnesium reagents enabled the single-step preparation of various arenes under mild reaction conditions and in yields of up to $99 \%$. We expect that this method will find a wide range of applications in discovery chemistry and sustainable process research, particularly in the synthesis of organic functional materials. Future studies will evaluate other selected substrate and reagent classes, the structure of the 1,5-bifunctional organomagnesium reagents, and the mechanism of this practical preparative method.

\section{Acknowledgements}

We gratefully acknowledge the Swiss National Sci-

ence Foundation for generous financial support, Novartis AG for an Excellence Scholarship for Life Sciences and Priv.-Doz. Dr. D. Häussinger for assistance with NMR spectroscopy. We thank Prof. K. Gademann and Prof. D. Seebach for helpful discussions.

Keywords: acenes · arenes - carboxylic acid esters ·

Grignard reactions · organomagnesium reagents

[1] a) Grignard Reagents: New Developments (Ed.: H. G. Richey, Jr.), Wiley, Chichester, 2000; b) The Chemistry of Organomagnesium Compounds (Eds.: Z. Rappoport, I. 
Marek), Wiley, Chichester, 2008; c) P. Knochel, A. Krasovskiy, I. Sapountzis in Handbook of Functionalized Organometallics: Applications in Synthesis (Ed.: P. Knochel), Wiley-VCH, Wein-heim, 2005; d) R. Mulvey, S. D. Robertson, Top. Organomet. Chem. 2013, 45, $103-140$.

[2] a) L. Boymond, M. Rottländer, G. Cahiez, P. Knochel, Angew. Chem. Int. Ed. 1998, 37, 1701-1703; Angew. Chem. 1998, 110, $1801-$ 1803 ; b) P. Knochel, W. Dohle, N. Gommermann, F. F. Kneisel, F. Kopp, T. Korn, I. Sapountzis, V. A. Vu, Angew. Chem. Int. Ed. 2003, 42, 4302-4320; Angew. Chem. 2003, 115, 44384456; c) A. Krasovskiy, P. Knochel, Angew. Chem. Int. Ed. 2004, 43, 3333-3336; Angew. Chem. 2004, 116, 3396-3399.

[3] a) K. Kitagawa, A. Inoue, H. Shinokubo, K. Oshima, Angew. Chem. Int. Ed. 2000, 39, 2481-2483; Angew. Chem. 2000, 112, 25942596; b) A. Inoue, K. Kitagawa, H. Shinokubo, K. Oshima, J. Org. Chem. 2001, 66, 4333-4339; c) T. lida, T.Wada, K. Tomimoto, T. Mase, Tetrahedron Lett. 2001, 42, 48414884; d) H. Yorimitsu, K. Oshima in Grignard Reagents: New Developments (Ed.: H. G. Richey, Jr.), Wiley, Chichester, 2000, chap. 15, pp. 681-715; e) F. Gallou, R. Haenggi, H. Wirt, W. Marterer, F. Schaefer, M. Seeger-Weibel, Tetrahedron Lett. 2008 , 49, 5024-5027.

[4] Examples for double halogen-metal exchange reactions to form 1,4bifunctional reagents: a) Z. Xi, Acc. Chem. Res. 2010, 43, 13421351; magnesiacyclopentadien: b) J. Wei, L. Liu, M. Zhan,

L. Xu, W.-X. Zhang, Z. Xi, Angew. Chem. Int. Ed. 2014, 53, 56345638; Angew. Chem. 2014, 126, 5740-5744.

[5] a) M. Fields, M. A. Leaffer, J. Rohan, Science 1949, 109, 35; b) A. Necula, A. Racoveanu-Schiketanz, M. D. Gheorghiu, L. T.Scott, J. Org. Chem. 1995, 60, 3448-3451; geminal disubstitution of carbonyl oxygens: c) D. Seebach, Angew. Chem. Int. Ed. 2011, 50, 96 - 101; Angew. Chem. 2011, 123, 99- 105.

[6] A nickel-catalyzed, decarbonylative organoboron cross-coupling reaction of carboxylic acid esters was recently reported: $\mathrm{K}$. Muto, J. Yamaguchi, D. G. Musaev, K. Itami, Nature Commun. 2015, doi: 10.1038/ncomms8508.

[7] Synthesis of 1 a via dibutyl-1-stanna-2,5-cyclohexadiene: a) P. Jutzi, J. Baumgartner, W. Schraut, J. Organomet. Chem. 1977, $132,333-338$.

[8] Synthesis of 1,4-pentadiyn-3-ol: a) E. R. H. Jones, H. H. Lee, M. C. Whiting, J. Chem. Soc. 1960, 3483-3489; used methods: b) H. Hofmeister, K. Annen, H. Laurent, R. Wiechert, Angew. Chem. Int. Ed. Engl. 1984, 23, 727 - 729; Angew. Chem. 1984, 96, $720-722$; c) C. Lüthy, P. Konstantin, K. G. Untch, J. Am. Chem. Soc. 1978, 100, $6211-6217$; d) D. P. Curran, H. Liu, H. Josien, S.-B. Ko, Tetrahedron 1996, 52, 11385-11404.

[9] For $3(\mathrm{M}=\mathrm{Li})$ and the reactivity with $\mathrm{Me}_{3} \mathrm{SiCl}$ and $\mathrm{Me}_{2} \mathrm{SiCl}_{2}$, see: Ref. [7]; with $\mathrm{ArGaCl}_{2}$ to gallatabenzene: a) A. J. Ashe III,

S. Al-Ahmad, J. W. Kampf, Angew. Chem. Int. Ed. Engl. 1995, 34, 1357 -1359; Angew. Chem. 1995, 107, 1479-1481; with
ArSnX 3 to stannabenzene: b) Y. Mizuhata, N. Noda, N. Tokitoh, Organometallics 2010, 29, 4781-4784.

[10] Li-Mg transmetalation: a) C. E. Tucker, T. N. Majid, P. Knochel, J. Am. Chem. Soc. 1992, 114, 3983-3985; b) M. S. Maji, T. Pfeifer, A. Studer, Chem. Eur. J. 2010, 16, 5872-5875; Mg insertion into 1,5-dibromopentane: c) V. Grignard, G. Vignon, C. R. Hebd. Seances Acad. Sci. 1907, 144, 1358-1360; into (Z)vinylalkyldibromide: d) P. Canonne, R. Boulanger, P. Angers, Tetrahedron Lett. 1991, 32, 5861-5864; I-Mg exchange with (Z)-alkenyl iodides and iPrMgCl-LiCl: e) H. Ren, A. Krasovskiy, P. Knochel, Org. Lett. 2004, 6, 4215-4217.

[11] A. Krasovskiy, B. F. Straub, P. Knochel, Angew. Chem. Int. Ed. 2006, 45, 159-162; Angew. Chem. 2006, 118, 165-169.

[12] Reactivity of bimetallic reagents in $X-M$ exchange reactions: $D$. Tilly, F. Chevallier, F. Mognin, P.C. Gros, Chem. Rev. 2014, 114, 1207 -1257; iodine-ate intermediates in X-M exchange reactions: a) H. J. Reich, N. H. Phillips, I. L. Reich, J. Am. Chem. Soc. 1985, 107, 4101-4103; b) V. Schulze, M. Brçnstrup, V. P.W.Bçhm, P. Schwerdtfeger, M. Schimeczek, R. W. Hoffmann, Angew. Chem. Int. Ed. 1998, 37, 824-826; Angew. Chem. 1998, 110, 869871; we assume that the magnesate character and the reactivity trends are largely transferred to the bifunctional organomagnesium reagents.

[13] Depending on the solvent, $R$, and $X$, the Schlenk equilibrium of di-Grignard reagents leads to differently associated cyclic and acyclic bifunctional organomagnesium reagents in equilibria at RT:

$$
\mathrm{XMgRMgX} \rightleftharpoons \frac{1}{n}+\mathrm{Mg}-\mathrm{R} f_{n}+\mathrm{MgX}_{2}
$$

Seminal studies: a) F. Bickelhaupt, Angew. Chem. Int. Ed. Engl. 1987, 26, 990-1005; Angew. Chem. 1987, 99, 1020-1035; b) M. A. G. M. Tinga, G. Schat, O. S. Akkerman, F. Bickelhaupt, E. Horn, H. Kooijman, W. J. J. Smeets, A. L. Spek, J. Am. Chem. Soc. 1993, 115, $2808 \quad-2817$; c) R. Fischer, R. Suxdorf, H. Gçrls, M. Westerhausen, Organometallics 2012, 31, 7579 -7585; struc-tural complexity of magnesates: d) D. Thoennes, E. Weiss, Chem. Ber. 1978, 111, 3726 -3731; e) R. E. Mulvey, F. Mongin, M. Uchiyama, Y. Kondo, Angew. Chem. Int. Ed. Engl. 1987, 26, $3802-$ 3824; Angew. Chem. 2007, 119, 3876 -3899; f) J. Francos, B. J. Fleming, P. García-Álvarez, A. R. Kennedy, K. Reilly, G. M. Robertson, S. D. Robertson, C. T. O'Hara, Dalton Trans. 2014, 43, 14424 14431.

[14] P. Jutzi, Z. Naturforsch. B 1969, 24, 354; the preparation of diaryldibromides for $3 \mathrm{~b}-\mathrm{d}$ is described in the Supporting Information. 